\title{
Assessment of public health issues of migrants at the Greek-Turkish border, April 2011
}

E Mertens (contact@elke-mertens.eu) ${ }^{1,2}$, G Rockenschaub ${ }^{3}$, A Economopoulou ${ }^{4}$, P Kreidl5

1. Postgraduate Training for Applied Epidemiology (PAE), Robert Koch Institute, Berlin, Germany

2. European Programme for Intervention Epidemiology Training (EPIET), European Centre for Disease Prevention and Control (ECDC), Stockholm, Sweden

3. World Health Organization (WHO) Regional Office for Europe, Copenhagen, Denmark

4. Hellenic Centre for Disease Prevention and Control, Athens, Greece

5. European Centre for Disease Prevention and Control, (ECDC), Stockholm, Sweden

Citation style for this article:

Mertens E, Rockenschaub G, Economopoulou A, Kreidl P. Assessment of public health issues of migrants at the Greek-Turkish border, April 2011.

Euro Surveill. 2012;17(2):pii=20056. Available online: http://www.eurosurveillance.org/ViewArticle.aspx?Articleld=20056

Article published on 12 January 2012

A joint mission to assess the public health situation of migrants in Greek detention centres was undertaken in April 2011 by the European Centre for Disease Prevention and Control (ECDC) and the World Health Organization (WHO) Regional Office for Europe. The assessment visit follows the increased migration to the Evros prefecture, Eastern Macedonia and Thrace region, at the Greek-Turkish border where large numbers of migrants are entering Greece via the Evros River, a natural border. Migrants are housed in local detention centres. The main problem in detention centres are the substandard hygiene conditions, especially overcrowding and lack of personal hygiene facilities, lack of basic supplies and lack of access to fresh air and physical exercise. As the migration route via the Evros region is increasingly used since 2009, and due to the unstable political situation in North Africa and the Middle East, an increased influx of migrants was to be expected with the falling water levels of the Evros River in summer, resulting in further deterioration of the already critical situation in the Thrace region's detention centres.

\section{Background}

Since the beginning of 2010, the number of migrants [1] that enter the Evros prefecture by crossing the GreekTurkish border has increased considerably. Until the end of 2009, approximately 3,500 migrants per year are reported to have entered the Evros prefecture in Greece by crossing the $206 \mathrm{~km}$ long Greek-Turkish border. The border follows the Evros River, hence the name of this prefecture [2]. During 2010, the number of migrants increased more than tenfold to 47,000 in the same region [3]. In October 2010, the European Agency for the Management of Operational Cooperation at the External Borders of the Member States of the European Union (FRONTEX), reported that Greece accounts for $90 \%$ of all detections of illegal border crossings in the European Union (EU) [4]. For the purpose of this report, 'migrants' are defined as including refugees, asylum seekers, displaced populations, irregular migrants and in some cases labour migrants, as defined by the International Organization for Migration (IOM) in the Glossary on Migration [1].

In the first months of 2011, the average number of migrants detected per day was about 58 in the Evros prefecture [5]. Migrants enter the region mainly by crossing the Evros. When water levels are high, migrants either swim or ferry over in small boats. In 2011, several persons have been reported to have died when crossing the border [6].

The increasing influx of migrants without documents in early 2011 led to massive overcrowding of the detention centres in the Evros prefecture and worsened the already poor humanitarian conditions that have been repeatedly criticised since 2005 by the European Committee for the Prevention of Torture and Inhuman or Degrading Treatment or Punishment and Amnesty International [7-11]. In addition to worsening humanitarian conditions, the overcrowding also increases the risk for the spread of communicable diseases such as tuberculosis, diarrhoea and respiratory infections [12].

The Greek Ministry of Health and Social Solidarity (MoHSS) had sought to address the health-related implications of overcrowding by setting up a project for the provision of healthcare inside the detention centres.

Additionally in March 2011, the Greek Health Minister invited representatives from the European Centre for Disease Prevention and Control (ECDC) and the World Health Organization (WHO) Regional Office for Europe to conduct a joint mission to the Thrace region.

The objective of the mission was to support Greek health authorities in assessing the public health situation in the detention centres for irregular migrants, with emphasis on communicable diseases, over- 
all health condition of the migrants and potential additional needs.

\section{Demographic features of migrants}

The geographical and cultural origin of migrants seems to vary. In March 2011, FRONTEX reported the largest groups of migrants in Evros as coming from Afghanistan (24\%), Pakistan (14\%) and Bangladesh (12\%) [5]. For the earlier period of August to December 2010, the Hellenic Centre for Disease Control and Prevention (HCDCP) had reported a total of 31 countries of origin, with Afghanistan (33\%) and the Occupied Palestinian Territory $(28 \%)$ being the most common, followed by Somalia (7\%), Morocco (6\%), Iraq and Algeria (4\% each).

Data on age and sex were available for 1,229 migrants apprehended at the Evros river outposts between 8 August 2010 and 12 December 2010. Most of them $(1,017 ; 83 \%)$ were male. Adolescents and young adults aged 12 to 40 years accounted for $91 \%$ (Data not shown).

\section{Detention}

Police authorities report that most migrants arrive without valid identification papers, such as passports or ID cards, and intend to claim asylum, mostly in other European countries such as Denmark, France, Germany, Norway, Sweden, Switzerland and the United Kingdom. According to Greek law, persons without identity papers shall be detained in closed centres for a maximum period of up to six months, until identification and nationality are validated. Lack of identity documents complicates the already bureaucratic and time-consuming process of seeking legal status [13], especially when the competent authorities are overburdened, and therefore prolongs the period of detention.

There are seven centres for migrants in the Eastern Macedonia and Thrace region, of which six are in the Evros prefecture [14]. One serves as a screening centre for entry assessment only and one for imprisoned traffickers only. Local police authorities are responsible for security and supplies in these centres which are often located within the local police stations. Most detention centres are regular police prisons having one to six cells, of variable size and with a maximum of two toilets and showers per cell. Only two centres have separate cells for women and families.

The five-month migrant healthcare project, 'Implementation of healthcare and psychosocial support activities for third country nationals that may require international protection in the area of EvrosGreece;, was implemented in March 2011 [15]. It aimed at providing medical and psychosocial support to detained persons. It was funded by the EU ( $80 \%)$ and by the Greek national authorities (20\%). Its implementation was under the responsibility and coordination of the HCDCP. Funding was limited to five months and ended in July 2011. Prior to March 2011, healthcare was mainly provided by medical doctors of the local authorities, non-governmental organisations such Médecins Sans Frontières (MSF) Greece and the HCDCP.

\section{Assessment visit}

In order to assess the public health situation of migrants in Greek detention centres, a joint mission was undertaken in April 2011 by the ECDC and the WHO Regional Office for Europe. The assessment was carried out through visits to detention centers and the University Hospital of Alexandroupolis, where interviews were carried out. The course of the visits and interviews in displayed in the Figure.

The mission team consisted of two senior experts from ECDC and WHO Regional Office for Europe and a fellow of the European Programme for Intervention Epidemiology Training (EPIET). The international team and Greek experts from the HCDCP and the MoHSS visited all detention and entry assessment centres, as well as the University Hospital of Alexandroupolis, where migrants are admitted if they need specialised

\section{FIGURE}

Course of visits and interviews, assessment visit to Greece, April 2011

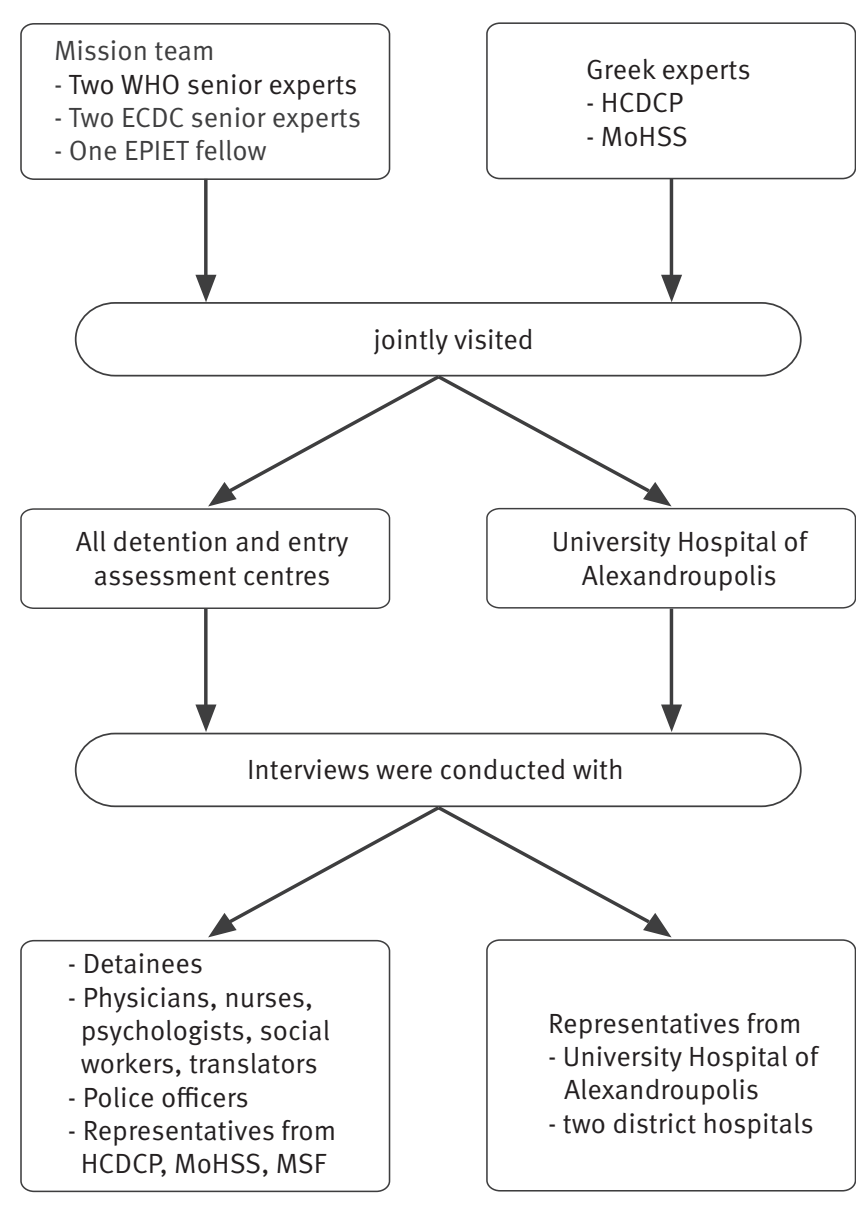

ECDC:European Centre for Disease Prevention and Control; EPIET: European Programme for Intervention Epidemiology Training; HCDCP: Hellenic Centre for Disease Prevention and Control; MoHSS: The Greek Ministry of Health and Social Solidarity; MSF: Médecins Sans Frontières; WHO: World Health Organization 
healthcare. The centre for traffickers was not visited. Unaccompanied minors (if stated age is less than 18 years) are sent to special centres for minors outside the Evros prefecture which minors can leave on demand. These centres were not visited during this mission.

In the detention centres, we conducted interviews with convenience samples of detained persons on their health, access to food, water, sleeping conditions, hygiene and what they regarded as the main problems of their situation. We also met representatives from MSF and gathered information on their assessment of the situation. Semi-structured interviews were conducted with representatives of the HCDCP, the MoHSS, the University Hospital of Alexandroupolis, two district hospitals, as well as with physicians, nurses, psychologists, social workers, translators and police officers at the detention and screening centres.

The 'health system crisis preparedness assessment method' [16], a tool available from the WHO, was used as framework during the three-day field visit. Minimum standards for occupancy $\left(3.5 \mathrm{~m}^{2}\right.$ per person) and hygiene conditions (one toilet per 20 persons) were assessed according to WHO emergency standards [17].

\section{Visit findings}

The visit findings are based on the mission teams' observations and semi-structured interviews. We interviewed two administrative employees of the migrant healthcare project and the programme manager, all from the HCDCP. In every centre, we interviewed (i) one to three police officers, (ii) one physician and one nurse working on site and (iii) ten to forty detainees. Of the staff that rotates between the centres, we interviewed one social worker, three translators and three psychologists.

\section{Basic conditions}

According to police authorities, a total of approximately 950 persons were detained in all five detention centres for migrants two days before our visit. Migrant fluctuation was high, as more than 200 persons had been released on the day prior to our visit, and more than 200 persons arrived in one of the centres during the two days of our visit. Occupancy varied between 75 in the smallest and 360 in the largest centre. According to the estimate of MSF representatives, the current number of detained persons therefore exceeded capacity two- to three-fold in four of the five detention centres (personal communication, MSF representatives, 6 April 2011). As far as the mission team could judge, none of the centres met the WHO minimum standard for occupancy of $3.5 \mathrm{~m}^{2}$ per person.

We were able to obtain data on length of stay from 27 detainees. Among them, the median period of detention was 30 days (range five to 210 days). Police authorities were not able to give reliable estimations of proportions of minors because their number was fluctuating strongly. That opinion was shared by the longest serving on-site physician.

In the interviews with police authorities, the most pressing concern was the further deterioration of the problems due to overcrowding, as the numbers of migrants were expected to increase as soon as the river's water level dropped in summer.

It was confirmed by several sources that unlimited drinking water was available in sufficient quality and quantity apart from in one centre were detainees reported the tap water to have a brownish colour and bad taste. Police officers and the healthcare team confirmed that the tap water in the whole village has a brownish colour due to high iron rust levels. Food was provided by catering services on a daily basis and was assessed by healthcare workers and most detainees to be sufficient in both quantity and quality. Two or three meals a day were made available to the migrants, consisting of bread alone for breakfast, and bread with mixed salad for lunch and dinner. In one centre, detainees reported that rations were insufficient on days when many new migrants arrived in the centre. The visiting team noted that no centre had cooling facilities for the salad boxes.

The visiting team further noted that hygienic conditions of toilets, cleanliness of premises and availability of personal hygiene resources were sub-standard. Detainees reported a lack of soap and detergents as well as too few toilets and showers. In four of five detention centres, police and detainees confirmed that less than one toilet was available per 20 persons. In one centre, 79 persons had to share one toilet and one shower.

All of the centres were undersupplied with beds, mattresses and blankets. Beds/mattresses and blankets had to be shared by two to four persons in two centres, according to detainees. In the remaining three centres, a substantial number of detainees had to sleep on the concrete floor; it was observed by the visiting team and confirmed by detainees that thin industrial felts instead of mattresses were available for only the half of the detainees. Detainees had very limited (once every three to four days) or no access to an outside yard/physical exercise. This was confirmed by police present at the centres.

The physician of the largest centre reported an average of two fights per month during which detainees are injured and have to be isolated for their own protection. Ethnicity and religion were not considered for assigning detainees to cells. However, women or families were detained separately from men.

\section{Health}

According to the HCDCP, an entry assessment of all migrants, psychosocial and medical support upon request, as well as a telephone-based early warning 
system were introduced under the newly established migrant healthcare project. Services were delivered by seven physicians, eight nurses, five psychologists and three social workers. The team was complemented by fourteen translators who covered Greek, English, French, Arabic, Farsi, Urdu, Pashto and Russian. Sustained healthcare provision to detained persons beyond the completion of the project is still under discussion. The services of the migrant healthcare project are described below.

\section{Entry medical examination and}

assessment of all migrants

In all six visited screening and detention centres, healthcare for inmates was provided by one to two nurses and one physician as established by interviews with several parties.

After apprehension, all migrants undergo a health check that consists of questions about their medical history and a clinical examination. Detained migrants are additionally tested for tuberculosis (Mantoux test) and their blood samples screened for hepatitis $B$, Crimean Congo haemorrhagic fever and syphilis. According to detention centre healthcare staff and the HCDCP, migrants apprehended but released due to decisions by police authorities, undergo the entry examination but not blood or tuberculosis screening, as follow-up treatment is not possible.

\section{Psychosocial support}

Psychological and social support is offered to detainees by psychologists and social workers, assisted by cultural mediators who rotate between the centres. A particular focus is on supporting children and adolescents, especially unaccompanied ones. All new migrants are screened by psychologists with the assistance of translators. During the first session, a standardised questionnaire for each migrant is filled in. Once an environment of trust is created, more details are collected in further sessions. For migrants suffering traumatisation, psychologists provide counselling in single and group sessions and are responsible for psychiatric referrals. The type of session as well as the number and intervals of sessions are determined by psychologists case by case. Psychologists are supported by translators during the sessions when possible. Social workers support detainees in handling administrative matters such as identity confirmation.

\section{Disease surveillance}

Health conditions as diagnosed during entry assessment and follow-up examinations are systematically documented after release from detention with a delay of approximately one week for data entry. Diseases that need immediate and/or specialised care are reported by the medical staff in the detention centres via telephone to the healthcare project manager.

In addition to entry assessments, physicians and nurses conduct daily assessments of the health of detainees by visiting the cells and treating patients on request. They assume an outbreak if they find more than three persons in one cell with similar respiratory or gastroenteric symptoms or fever. Additionally, the project manager receives written summaries of the migrants' health from all detention centres on a daily basis.

The HCDCP and healthcare staff reported three cases of tuberculosis between March and mid-July 2011, but no outbreaks of communicable diseases were noted.

Vaccination

As part of the migrant healthcare project, children ( 18 years) are vaccinated against diphtheria, tetanus, pertussis, polio, measles, mumps and rubella. Adults are vaccinated against diphtheria, tetanus and polio. These vaccinations are administered to all detainees because the migrants without identity documents do not have vaccination cards and their vaccination status cannot be validated. The staff at detention centres is encouraged to get vaccinated against the same diseases as adult detainees. Vaccines against diphtheria, tetanus and polio are available for staff at the centres where they work.

\section{Specialised healthcare}

Migrants who need specialised healthcare are referred to the University Hospital of Alexandroupolis (670 beds) or one of two district hospitals (217 and 150 beds) in the Evros prefecture.

\section{Conclusion}

The main problem in all visited detention centres were the substandard hygiene conditions, especially overcrowding and lack of personal hygiene facilities, lack of basic supplies and lack of access to fresh air and physical exercise. The very poor humanitarian conditions in the centres needed to be improved urgently. In order to limit the risk for outbreaks of vaccine-preventable diseases, vaccination of detainees, healthcare workers and other staff in the centres should be continued. There was no evidence for immediate threats to the health of the Greek population originating from the migrants.

Considering the traumatisation many migrants have gone through, the psychosocial support services also need to be sustained and increased. The severe overcrowding should be addressed as it increases the risk for communicable diseases such as diphtheria, tetanus and polio spreading, psychosocial distress and the aggravation of traumatisation, as well as causing potentially violent conflicts.

As the migration route via the Evros region is increasingly used since 2009, and due to the unstable political situation in North Africa and the Middle East, an increased influx of migrants is to be expected with the falling water levels of the Evros River in summer, resulting in further deterioration of the already critical 
situation in the Thrace region's detention centres. EU Member States should share public health best practices for managing detention centres.

According to the police authorities, the translators and detainees, the implementation of the migrant healthcare project has greatly improved access to healthcare including psychosocial support for migrants. The early warning system that was introduced by the migrant healthcare project, was based on personal communication, vulnerable to human and technical errors and depended on the presence of the project manager. During the time between the assessment visit and the submission of this article, a syndromic surveillance system was developed and successfully implemented within the framework of the EPIET programme [18].

\section{Acknowledgments}

The ECDC and WHO Regional Office for Europe would like to thank the Hellenic Centre for Disease Prevention and Control and the Ministry for Health and Social Solidarity for their hospitality, the effective mission preparations and the openness and transparency during the visit.

The authors thank Florian Burckhardt, Katharina Alpers, Ioannis Karagiannis and Evelyn Depoortere, for their comments and encouragement.

\section{Full report}

The ECDC Mission report [19] is available from http://www. ecdc.europa.eu/en/publications/Publications/1105_MIR Joint_WHO_Greece.pdf

\section{References}

1. International Organization for Migration (IOM). Glossary on Migration [Internet]. Geneva: IOM; 2004 [accessed 2011 May 11]. Available from: http://www.iom.int/jahia/webdav/site/ myjahiasite/shared/shared/mainsite/published_docs/serial publications/Glossary_eng.pdf

2. Central Intelligence Agency (CIA) The world factbook, Greece. [accessed 2011 April 12]; Available from: https://www.cia.gov/ library/publications/the-world-factbook/geos/gr.html

3. FRONTEX. Press Pack may 2011: FRONTEX; 2011 [accessed 2011 October 09]. Available from: http://www.frontex.europa.eu/ newsroom/news_releases/art98.html

4. Frontex Frontex deploys Rapid Border Intervention Teams to Greece. Frontex European Union Agency; 2010 [accessed 2011 July 27]; Available from: http://www.frontex.europa.eu/ newsroom/news_releases/art79.html.

5. FRONTEX RABIT Operation 2010 Ends, Replaced By JO Poseidon 2011. FRONTEX; 2011 [accessed 2011 May 11]; Available from: http://www.frontex.europa.eu/newsroom/ news releases/art98.html

6. Médecins Sans Frontières (MSF) [Internet]. Greece: Immediate action needed to improve unbearable living conditions.2011 [updated 2011 Jan 26; accessed 2011 May 11]; Available from: http://www.msf.org.uk/Evros_living_conditions_20110126. news

7. CPT. Report to the Government of Greece on the visit to Greece carried out by the European Committee for the Prevention of Torture and Inhuman or Degrading Treatment or Punishment (CPT) from 27 August to 9 September 2005 [Internet]. Strasbourg: CPT; 2006 [accessed 2011 May 11]. Available from: http://www.cpt.coe.int/documents/grc/2006-41-inf-eng.htm.

8. CPT. Report to the Government of Greece on the visit to Greece carried out by the European Committee for the Prevention of Torture and Inhuman or Degrading Treatment or Punishment (CPT) from 20 to 27 February 2007 [Internet]. Strasbourg: CPT; 2008 [accessed 2011 May 11]. Available from: http://www.cpt. coe.int/documents/grc/2008-03-inf-eng.htm.
9. СРT. Report to the Government of Greece on the visit to Greece carried out by the European Committee for the Prevention of Torture and Inhuman or Degrading Treatment or Punishmen (CPT) from 17 to 29 September 2009 [Internet]. Strasbourg: CPT; 2010 [accessed 2011 May 11]. Available from: http://www. cpt.coe.int/documents/grc/2010-33-inf-eng.htm

10. CPT [Internet]. Strasbourg. Public statement concerning Greece. European Committee for the Prevention of Torture and Inhuman or Degrading Treatment or Punishment (CPT) 2011 [updated 2011 March 15; accessed 2011 May 11]; Available from: http://www.cpt.coe.int/documents/grc/2011-10-inf-eng.htm

11. Amnesty International [Internet]. Greece must urgently remedy deplorable detention conditions.2011 [updated 2011 March 16; accessed 2011 May 11]; Available from: http://www.amnesty. org/en/library/asset/EUR25/006/2011/en/14f92528-a12942d4-9053-a25a99a2edba/eur250062011en.html

12. European Centre for Disease Prevention and Control (ECDC). Risk assessment: Situation in northern Africa/Libyan Arab Jamahiriya and the influx of migrants to Europe. 2011. 2011. Available from: http://ecdc.europa.eu/en/publications/ Publications/Forms/ECDC_DispForm.aspx?ID $=667$

13. European Commission. Clandestino Project. Final Report. Athens: European Commission 2009.

14. GlobalDetentionProject Greece Detention Profile. GlobalDetentionProject; 2009 [updated November 2009; accessed 2011 May 11]; Available from: http://www. globaldetentionproject.org/countries/europe/greece/ introduction.html

15. Hellenic Centre for Disease Prevention and Control (HCDCP) Evros Project. HCDCP; [accessed 201126 October]; Available from: http://www2.keelpno.gr/ blog/?cat=10\&lang=en\&paged $=2$

16. World Health Organization (WHO). Health Needs Assessment, Malta [Internet]: WHO; 2011 [accessed 2011 July 01]. Available from: http://www.euro.who.int/ data/assets/pdf file/0011/144011/Health_Needs_Assess_Malta_2011.pdf

17. World Health Organization (WHO). Communicable disease control in emergencies: a field manual [Internet]: WHO; 2005 [accessed 2011 May 11]. Available from: http://www. who.int/infectious-disease-news/IDdocs/whocds200527/ ISBN_9241546166.pdf

18. Bosman A, Schimmer B, Coulombier D. Contribution of EPIET to public health workforce in the EU, 1995-2008. Euro Surveill. 2009;14(43).

19. European Centre for Disease Prevention and Control (ECDC). MISSION REPORT: Increased influx of migrants at the Greek-Turkish border: European Centre for Disease Prevention and Control (ECDC); 2011 [accessed 2011 May 28]. Available from: http://www.ecdc.europa.eu/en/publications/ Publications/1105_MIR_Joint_WHO_Greece.pdf 